\title{
Perspektif Mahasiswa: Evaluasi Program Pendidikan Profesi Dokter Rotasi Kedokteran Keluarga di Fakultas Kedokteran Universitas Padjadjaran, Bandung Indonesia
}

\author{
Nita Arisanti, Elsa Pudji Setiawati \\ Departemen Ilmu Kesehatan Masyarakat Fakultas Kedokteran Universitas Padjadjaran
}

\begin{abstract}
Abstrak
Berbagai inovasi dalam pendidikan kedokteran harus selalu dilakukan. Salah satu inovasi yang dilakukan adalah pengembangan Kurikulum PSPD Kedokteran Keluarga. Evaluasi program sangat diperlukan agar dapat diterapkan dengan baik. Evaluasi merupakan bagian integral pelaksanaan dan pengembangan kegiatan pendidikan, Tujuan penelitian ini adalah untuk mendapatkan gambaran evaluasi Program PSPD dari perspektif mahasiswa yang telah melakukan rotasi. Disain penelitian adalah deskriptif kuantitatif terhadap seluruh mahasiswa FK Unpad yang telah melakukan rotasi di PSPD Kedokteran Keluarga selama 6 bulan program diterapkan yaitu Januari - Agustus 2011. Tehnik pengambilan sampling secara total sampling terhadap 68 mahasiswa yang telah melakukan rotasi. Pengambilan data dengan kuesioner dan dianalisis dengan distribusi frekuensi. Hasil penelitian menggambarkan penilaian peserta didik terhadap tujuan, metode pembelajaran, modul, lembar kerja, metode asesmen, wahana pendidikan, pembimbing dan pendukung program. Gambaran tentang tujuan pendidikan didapatkan sebagian besar $(96 \%)$ responden menyatakan program sudah sesuai kompetensi dan dapat dicapai melalui metode pembelajaran yang diberikan. Kompetensi juga dapat dicapai melalui alokasi waktu yang tersedia. Sebanyak 57\% mahasiswa memberikan penilaian positif terhadap bahan ajar, terutama penilaian mengenai referensi dan tugas yang diberikan. Penilaian untuk lembar kerja mahasiswa, didapatkan ketidaksesuaian antara tugas pada lembar kerja dan pembekalan. Perlu evaluasi berkala untuk menilai pelaksanaan program dan beberapa hal perlu diperbaiki sesuai dengan umpan balik peserta didik.
\end{abstract}

Kata kunci: Evaluasi, profesi dokter, program pendidikan

\section{Evaluation of new family medicine clerkship program from the perspectives of students in Faculty of Medicine Universitas Padjadjaran, Bandung Indonesia}

\begin{abstract}
The medical curriculum had been changed into competency-based curriculum since 2005. One of these competencies is apply principles of basic biomedical, clinical, behavioural sciences and epidemiology in the practice offamily medicine. To achieve this competency, a rotation in family medicine had been inserted into medical curriculum. The study objective was to evaluate the implementation of a new family medicine rotation' curriculum. The study method was cross sectional. A questionnaire was given to student after a rotation in family medicine. The period of this study was January - August 2011. The data was analyzed using distribution frequency. The results of this study were most of respondent (97\%) agreed that the Program objectives are met and the mode of delivery is suitable for improving and implementing the knowledge and skills; most of respondent stated that the worksheets are complicated, but the module is useful. In term of evaluation methods, majority of respondent agreed that the tools are measurable and objective. The conclusions are the program achieved its objectives and necessary changes based on this study should be considered.
\end{abstract}

Keywords: Educational program, evaluation, medical profession

Korespondensi :

Nita Arisanti,dr., M.Sc-FM

Departemen Ilmu Kesehatan Masyarakat Fakultas Kedokteran Universitas Padjadjaran

Jl. Eijkman No. 38 Bandung

Email : nitarisanti@yahoo.com 


\section{Pendahuluan}

Pendidikan Profesi adalah pendidikan tinggi setelah program sarjana yang mempersiapkan peserta didik untuk memiliki pekerjaan dengan persyaratan keahlian khusus Pendidikan Kedokteran merupakan salah satu program pendidikan profesi yang bertujuan untuk menghasilkan dokter yang mampu melaksanakan tugas profesinya dan senantiasa memiliki keinginan untuk meningkatkan dan mengembangkan diri sesuai dengan tuntunan profesionalitas seorang dokter. Melalui Pendidikan Kedokteran yang paripurna diharapkan dokter yang dihasilkan memiliki sikap dan dapat mengembangkan kepribadian yang diperlukan untuk menjalankan profesinya seperti integritas, rasa tanggung jawab, dapat dipercaya sesuai dengan etika profesinya yang universal.

Pendidikan di Program Studi Profesi Dokter di Fakultas Kedokteran Unpad dilaksanakan dengan menggunakan metode pelatihan berdasarkan kompetensi (Competency-based Training), yang meliputi kompetensi klinik dan manajemen kesehatan masyarakat. Program Studi Profesi Dokter (PSPD) terdiri dari rotasi pada 16 departemen yang dilalui dalam waktu 3 semester. Setelah tahap ini diselesaikan diharapkan dokter muda telah memiliki kompetensi sebagai dokter.

Dokter yang dihasilkan harus memiliki kemampuan sesuai dengan Standar Kompetensi Dokter Indonesia (SKDI) yang disahkan oleh Konsil Kedokteran Indonesia dan mampu berperan serta dalam Sistem Kesehatan Nasional dan mengikuti perkembangan global ilmu kedokteran untuk meningkatkan kualitas kesehatan masyarakat. Standar Kompetensi Dokter Indonesia disusun atas dasar 6 butir tanggung jawab Dokter Layanan Primer, panduan WHO, Standar Global WFME (World Federation of Medical Education), contoh-contoh berbagai kurikulum di FK-FK di dunia dan Visi Indonesia Sehat 2010. Lulusan FK diharapkan dapat menerapkan Ilmu Biomedik, Ilmu Humaniora, Ilmu Kedokteran Klinik, dan Ilmu Kesehatan Masyarakat/Kedokteran Pencegahan/Kedokteran Komunitas yang terkini untuk mengelola masalah kesehatan secara holistik dan komprehensif, sehingga Ilmu Kedokteran Keluarga dan Manajemen Pelayanan Kesehatan Primer harus diberikan pada mahasiswa fakultas kedokteran. ${ }^{1}$

Untuk mendapatkan lulusan yang diharapkan, berbagai inovasi dalam pendidikan kedokteran harus selalu dilakukan. Salah satu inovasi yang dilakukan adalah pengembangan Kurikulum PSPD rotasi Kedokteran Keluarga. Agar dapat diterapkan dengan baik, evaluasi program sangat diperlukan. Evaluasi merupakan bagian integral dari pelaksanaan dan pengembangan kegiatan pendidikan, baik program nasional ataupun kurikulum sekolah bahkan dapat menjadi bagian dari pekerjaan yang dilakukan oleh pendidik atau mahasiswa. ${ }^{2}$ Perbaikan program melalui evaluasi program ini adalah respon dari ketidakpuasan tim pengembang kurikulum terhadap pelaksanaan program, dimana penilaian program darisisi proses jarang dilakukan. ${ }^{1}$ Tujuan penelitian ini adalah untuk mendapatkan gambaran evaluasi program PSPD dari perspektif mahasiswa yang telah melakukan rotasi periode tahun ajaran 2012/2013.

\section{Metode}

Disain penelitian yang digunakan adalah deskriptif kuantitatif terhadap seluruh mahasiswa yang telah melakukan rotasi di PSPD kedokteran keluarga selama 6 bulan program ini diterapkan. Kriteria inklusi adalah mahasiswa telah mengikuti secara keseluruhan rotasi PSPD kedokteran keluarga dan bersedia mengikuti penelitian ini. Tehnik pengambilan sampling secara total sampling dilakukan terhadap 68 mahasiswa yang telah melakukan rotasi. Terdapat 10-12 mahasiswa setiap rotasinya. Pengambilan data dilakukan dengan menyebarkan kuesioner. Dimensi evaluasi program terdiri dari tujuan dan metode pembelajaran, modul pembelajaran dan lembar kerja, metode asesmen, tempat dan lama rotasi serta pembimbing. Kemudian dilakukan analisis data dengan menggunakan distribusi frekuensi. Penelitian ini dilakukan pada bulan Januari - Agustus 2011 di FK Unpad.

\section{Hasil}

Evaluasi dilakukan dengan menyebarkan kuesioner kepada 68 mahasiswa yang telah melakukan rotasi di PSPD Kedokteran Keluarga selama lima minggu. Mahasiswa ditempatkan di puskesmas atau klinik jejaring FK Unpad dan mendapat bimbingan dari dokter/ pembimbing lapangan dan dokter/ pembimbing departemen. Evaluasi program ini merupakan penilaian terhadap pendapat peserta didik mengenai tujuan pembelajaran, metode pembelajaran, modul/ bahan ajar, lembar kerja, metode asesmen, wahana pendidikan, pembimbing dan pendukung program. Gambaran tentang tujuan pendidikan didapatkan sebagian besar responden menyatakan kegiatan PSPD ini sudah sesuai dengan kompetensi yang harus didapat oleh mahasiswa dan dapat dicapai melalui metode pembelajaran yang diberikan. Kompetensi ini juga dapat dicapai melalui alokasi waktu yang 
Nita Arisanti : Perspektif Mahasiswa: Evaluasi Program Pendidikan Profesi Dokter Rotasi Kedokteran Keluarga di Fakultas Kedokteran Universitas Padjadjaran, Bandung Indonesia

tersedia, seperti digambarkan pada Tabel 1. Pada kegiatan PSPD ini, mahasiswa dibekali dengan bahan ajar yang memuat prinsip-prinsip dasar kedokteran keluarga dalam penatalaksanaan pasien. Dari tabel diatas didapatkan bahwa hanya sebagian kecil mahasiswa memberikan penilaian positif terhadap bahan ajar, terutama penilaian mengenai referensi dan tugas yang diberikan. Pada Tabel 2 menggambarkan penilaian untuk lembar kerja mahasiswa, didapatkan ketidaksesuaian antara tugas pada lembar kerja dan pembekalan yang diberikan pada awal rotasi PSPD Kedokteran Keluarga ini.

Tabel 1. Gambaran penilaian mahasiswa terhadap tujuan, metode modul, lembar kerja dan metode asesmen

\begin{tabular}{lcc}
\hline \multicolumn{1}{c}{ Variabel } & Jumlah & Frekuensi (\%) \\
\hline 1. Tujuan pembelajaran & & \\
- Sesuai dengan kompetensi yang harus dicapai oleh mahasiswa & 65 & 96 \\
- Dapat dicapai dengan kegiatan pembelajaran & 59 & 87 \\
- Dapat dicapai dengan alokasi waktu yang tersedia & 53 & 78 \\
2. Metode pembelajaran & & \\
- Sesuai dengan tujuan pendidikan & 61 & 90 \\
- Memberi kesempatan untuk menambah pengetahuan & 65 & 96 \\
- Memberi kesempatan untuk menambah keterampilan & 63 & 93 \\
- Terdapat kesempatan untuk belajar mandiri & 61 & 90 \\
3. Modul bahan ajar & & \\
- Memuat ilmu dasar yang harus dikuasai & 39 & 57 \\
- Penyajian modul ringkas & 60 & 88 \\
- Bahasa cukup dimengerti & 61 & 90 \\
- Tugas di akhir modul memberi manfaat & 48 & 71 \\
- Referensi cukup & 35 & 51 \\
- Referensi up to date & 50 & 74 \\
4. Lembar kerja & & 75 \\
- Sesuai dengan tujuan pendidikan & 51 & 72 \\
- Terlalu banyak yang harus diisi & 49 & 37 \\
- Sesuai dengan kuliah dan pembekalan & 25 & 76 \\
5. Asesmen & & 71 \\
- Metode evaluasi sesuai dengan tujuan pembelajaran & 52 & \\
- Metode evaluasi obyektif & 48 & \\
\hline
\end{tabular}


Nita Arisanti : Perspektif Mahasiswa: Evaluasi Program Pendidikan Profesi Dokter Rotasi Kedokteran Keluarga di Fakultas Kedokteran Universitas Padjadjaran, Bandung Indonesia

Tabel 2. Gambaran penilaian mahasiswa terhadap wahana, alokasi waktu, pembimbing dan pendukung program

\begin{tabular}{lcc}
\hline \multicolumn{1}{c}{ Variabel } & Jumlah & Frekuensi (\%) \\
\hline 1. Wahana & & \\
- Sesuai dengan tujuan pembelajaran & 61 & 90 \\
- Jumlah kasus memadai & 50 & 74 \\
- Mudah dicapai & 51 & 75 \\
- Nyaman & 59 & 87 \\
2. Waktu, dibandingkan dengan tujuan pembelajaran & & \\
- Terlalu lama & 13 & 19 \\
- Cukup & 50 & 74 \\
- Terlalu singkat & 7 & 10 \\
3. Preceptor/ pembimbing departemen & & \\
- Memberikan dukungan dan bimbingan & 58 & 85 \\
- Mudah dihubungi & 64 & 94 \\
- Memberikan ilmu yang cukup sesuai dengan tujuan pendidikan & 48 & 71 \\
4. Preceptor/ pembimbing lapangan & & 88 \\
- Memberikan dukungan dan bimbingan & 60 & 97 \\
- Mudah dihubungi & 66 & 85 \\
- Memberikan ilmu yang cukup sesuai dengan tujuan pendidikan & 58 & \\
5. Pendukung kegiatan & & 91.2 \\
- Petugas administrasi departemen IKM membantu & 62 & 36.8 \\
- Petugas administrasi PSPD membantu & 56 & \\
• Dokumen terlalu banyak & 25 & \\
\hline
\end{tabular}

\section{Pembahasan}

Evaluasi program adalah suatu unit atau kesatuan kegiatan yang bertujuan mengumpulkan informasi tentang realisasi atau implementasi dari suatu kebijakan, berlangsung dalam proses yang berkesinambungan, dan terjadi dalam suatu organisasi yang melibatkan sekelompok orang guna pengambilan keputusan. Dalam pendidikan istilah ini sering digunakan bergantian dengan penilaian.Penilaian terutama berkaitan dengan pengukuran kinerja siswa, evaluasi umumnya merujuk pada proses mendapatkan informasi tentang program pengajaran untuk selanjutnya sebagai masukan dalam pengambilan keputusan.2 Penelitian tentang evaluasi program merekomendasikan agar evaluasi dilakukan sebelum, saat berlangsung dan setelah program dilaksanakan. Manfaatnya adalah evaluasi dilakukan cukup ketat yang memungkinkan dapat diimplementasikan pada seluruh spektrum pendidikan kedokteran. ${ }^{3}$ Dua tujuan utama evaluasi program adalah untuk menilai metode pembelajaran dan menilai efektifitas dari program.2 Direktur/ manajer program, clerkship, dan residensi bertanggung jawab tidak hanya untuk menentukan apakah mahasiswa telah mencapai tujuan pendidikan tetapi juga untuk memastikan kualitas program itu sendiri. ${ }^{3}$

PSPD Kedokteran Keluarga merupakan program baru di FK Unpad, sehingga untuk keberlangsungan program ini, enam bulan pertama perlu dilakukan evaluasi untuk menilai efektifitas program terhadap mahasiswa, untuk mendokumentasikan bahwa tujuan pendidikan telah tercapai, memberikan informasi mengenai program sehingga dapat dilakukan perbaikan., ${ }^{2,4}$ Menurut salah satu penelitian ada beberapa tipe program evaluasi yaitu evaluasi berorientasi tujuan, evaluasi berorientasi proses dan evaluasi berorientasi peserta. ${ }^{5}$. Penelitian ini merupakan evaluasi berorientasi peserta didik dimana pendekatan ini mencari persepsi yang terlibat terhadap program. Dalam program evaluasi terdapat beberapa topik yang dapat dinilai. Penelitian di UEA melakukan penilaian 
terhadap program residensi dan menilai aspek lama bertugas, pembimbing, metode penilaian, isi pembelajaran, dan pendukung. Penelitian ini menggunakan survey dengan kuesioner yang diberikan kepada residen di 6 institusi pendidikan. ${ }^{6}$ Penelitian lain menyebutkan bahwa dalam menlakukan evaluasi program, beberapa hal yang dapat diperbaiki setelah mendapatkan umpan balik dari peserta adalah perilaku pembimbing, tujuan pembelajaran, tujuan program dan dapat juga dinilai kepuasan peserta. ${ }^{7}$ Dengan adanya evaluasi program ini, pengelola program dapat mengetahui poin-poin mana yang harus diperbaiki dan poin mana yang harus dipertahankan. Penelitian mengenai evaluasi program CME untuk dokter menyebutkan bahwa inovasi baru diperlukan untuk dapat memberikan kebutuhan dan tuntutan dari peserta didik. ${ }^{7}$ Berdasarkan penilaian mahasiswa beberapa hal yang perlu diperbaiki dari PSPD Kedokteran Keluarga ini antara lain adalah bahan ajar/ modul, lembar kerja mahasiswa dan metode penilaian. Penelitian di Iran juga menyebutkan, bahwa beberapa perbaikan harus dilakukan agar tujuan program pembelajaran tercapai. Menurut penelitian ini hal yang perlu diperbaiki antara lain adalah penggunaan metode penilaian peserta didik yang lebih modern dan sesuai dengan perkembangan dunia pendidikan kedokteran. ${ }^{8}$ Program evaluasi harus dilakukan sesuai kebutuhan di lapangan. 9,10

Keterbatasan penelitian ini adalah adanya bias dalam mengisi kuesioner ini karena peserta didik menjawab sendiri kuesioner tersebut. Simpulan penelitian ini adalah sebagian besar responden menyatakan kegiatan PSPD ini sudah sesuai dengan kompetensi yang harus didapat oleh mahasiswa dan dapat dicapai melalui metode pembelajaran yang diberikan. Kompetensi ini juga dapat dicapai melalui alokasi waktu yang tersedia. Penilaian untuk lembar kerja mahasiswa didapatkan ketidaksesuaian antara tugas pada lembar kerja dan pembekalan. Saran dari penelitian ini adalah perlu adanya evaluasi yang berkala untuk menilai pelaksanaan program dan beberapa hal yang perlu diperbaiki agar dapat ditindaklanjuti oleh pengelola program sesuai dengan umpan balik dari peserta didik.

\section{Daftar Pustaka}

1. Fakultas Kedokteran Unpad. Pedoman PendidikanProgramStudiProfesiDokter.2013

2. Goldie J. AMEE Education Guide no. 29: Evaluating educational programs. Medical Teacher. 2006;28(3):210-24.

3. Durning SL, Hemmera P, Pangaroa LN. The Structure of Program Evaluation: An Approach for Evaluating a Course, Clerkship, or Components of a Residency or Fellowship Training Program. Teaching and Learning in Medicine. 2007;19(3):308-18.

4. Musick DW. A Conceptual Model for Program Evaluation in Graduate Medical Education. Acad Med. 2006;81:759-65.

5. Cook DA. Twelve tips for evaluating educational programs. Medical Teacher. 2010; 32: 296-301.

6. Ibrahim H, Lindeman B, Matarelli SA, Chandrasekhar S. International Residency Program Evaluation: Assessing the Reliability and Initial Validity of the ACGME-I Resident Survey in Abu Dhabi, United Arab Emirates. Journal of Graduate Medical Education. 2014:517-20.

7. Moattari M, Yadgari D, Hoseini SJ. The evaluationofacomposedprogramofcontinuing medical education for general practitioners. J Adv Med Educ Prof. 2014;2(3): 120-5.

8. Shahidi F. Saqeb MM, Amini M, Avand A, Dowlatkhah HR. Qualitative evaluation of general practitioner training program as viewed by graduates from Shiraz, Fasa and Jahrom Medical Universities. J Adv Med Educ Prof. 2015;3(3):142-9.

9. Boggan, JC, et al. A Novel Approach to Practice-Based Learning and Improvement Using a Web-Based Audit and Feedback Module. Journal of Graduate Medical Education.2014: 541-6.

10. Kojuri J, et al. Needs assessment and evaluation of a short course to improve faculties teaching skills at a former World Health Organization regional teacher training center. J Adv Med Educ Prof. 2015;3(1): 1-8. 